\title{
Impact of Pesticides on Soil Microbial Diversity and Enzymes: A Review
}

\author{
Yumnam Bijilaxmi Devi ${ }^{{ }^{*}}$, Thounaojam Thomas Meetei ${ }^{2}$ and Nirmala Kumari ${ }^{2}$ \\ ${ }^{1}$ Department of Soil Science, NRM Division, ICAR Research Complex for NEH Region, \\ Umiam - 793103, Meghalaya, India \\ ${ }^{2}$ Department of Soil Science and Agricultural Chemistry, Palli Siksha Bhavana, Visva- \\ Bharati, Sriniketan - 731236, West Bengal, India \\ *Corresponding author
}

\begin{tabular}{|l|}
\hline K e y w o r d s \\
Biopesticide, \\
$\begin{array}{l}\text { Degradation, } \\
\text { Enzymes, Microbial } \\
\text { diversity, Pesticides }\end{array}$ \\
\hline Article Info \\
\hline $\begin{array}{l}\text { Accepted: } \\
\text { 06 May 2018 } \\
\text { Available Online: } \\
\text { 10 June } 2018\end{array}$ \\
\hline
\end{tabular}

A B S T R A C T

Intensive agriculture has been successful owing to its input viz. fertilizers and pesticides along with high yielding varieties. But due to xenobiotic characteristics of pesticides in soil, it may adversely affect the growth of beneficial microorganisms and transformations associated with them. Pesticide contamination is a major concern in current scenario of agriculture. Microorganisms influence important biochemical reactions such as mineralization of organic matter, nitrification, ammonification etc. The impact of pesticides on microbial diversity and enzymatic activities are of significance as bio-transformations play key role in biochemical reactions and degradation of pesticides in soil to maintain soil health. Degradation of pesticides depends on many factors viz. pesticide structure and concentration, temperature, $\mathrm{pH}$ and soil moisture etc. Pesticides inhibit or kill certain group of microorganisms by reducing the competition of certain groups; it reduces microbial diversity but increases functional diversity of microbial communities. Inactivation of nitrogen fixing and phosphorus solubilizing microorganisms is observed in pesticide contaminated soils. However, few reports have highlighted some positive effects of pesticides on soil microbial diversity as some microbes are capable of utilizing applied pesticides as a source of energy and nutrients for their growth. Biopesticides are also gaining importance as they can be an alternative to chemical pesticides in sustaining natural environment. Trichoderma has been observed to increase microbial flora and fauna by improving soil aggregation. However, certain bio-pesticides may stimulate shifting of specific microbial population thus changing the microbial community. Negative impact of a microbial biopesticide, paenimyxin produced by Paenibacillus sp. strain B2 was observed on the bacterial population. It is difficult to understand the role of pesticides in disconcerting soil environment due to conflicting research findings available in the literature. Therefore, application of biopesticides along with natural soil amendments (compost, manure, vermicompost etc.) can be an alternative to chemical pesticides without deteriorating the environment but complete removal of chemical pesticides may not be advisable as biopesticides are slow in action. 


\section{Introduction}

World is facing population crisis, in order to cope up with the expanding population, higher food production is necessary to meet the food demand of the growing population. As $3 / 4^{\text {th }}$ part of the earth is covered by water, land is very much limited for expanding crop cultivation. So, in vision of increasing the production of crops, increasing crop productivity in the limited land available is the only option which can be achieved only through intensive agriculture. Judicious use of inorganic fertilizers and pesticides may not jeopardize the natural environment, but the increased pressure on these chemicals has caused indiscriminate use of these chemicals hopeful to increase productivity at a higher and faster rate which will bring consequences in the later future. Indiscriminate use of these chemicals has reportedly been found to be deteriorating soil health as well the environment as a whole (Ejaz et al., 2004). Among these chemicals, pesticides, which are used to control pest in the soil and plant may also have some adverse effect on soil health besides providing security to the crop from pest.

Alterations due to disturbance aroused after application of excessive application of agrochemicals such as inorganic fertilizers and a range of pesticides (Wilson, 2000). Pesticides may affect soil microbial communities which are associated with many key functions in the soil to maintain soil health (Mahía et al., 2008). Enzymatic activities are also among the most important key component in environment which triggers any chemical reactions occurring in the nature. As enzymes are associated with microbial population in the soil, enzymatic activities and biological processes may suffer some adverse impact from pesticides application (Antonious, 2003). So, pesticide contamination is one of the important aspects nowadays as they are polluting the environment as well. In order to minimize the effect of chemical pesticides on environment, use of bio-pesticides is gaining importance. It is believed that such natural pesticides are safer and less damaging to the ecosystem however; these may also affect the ecosystem adversely (Gopal et al., 2013). The numbers of fungi and nitrifiers are reported to be reduced significantly after application of azadirachtin at recommended doses while higher doses have high biocidal effects of soil microorganisms and its activities (Gopal et al., 2007). This may be due to their antagonistic properties to each other. Therefore, study on impacts of chemical as well as bio-pesticides on soil microbial diversity and enzymes is crucial as ultimately soil is the sink of these substances.

Microbial communities in soil ecosystems provide various important functions like decomposition of organic material, recycling of nutrients, nitrogen and carbon cycle, storage and release of nutrients, plant growth promotion and by providing a major food source at the base of food webs. Microbes are also capable of degrading soil-associated organic pollutants and can thus contribute to remediation of contaminated ecosystems which reduces the effect of pollution. Thus, many microbial functions are critical to crop production, soil sustainability, and environmental quality and the impact of pesticides on the diversity of soil microbial communities and enzymatic activities become vital (Gupta et al., 2013). Non target organism exposure and offsite mobility of the applied pesticides have become a major concern in respect to keep the environment contaminants free (Hafez and Theimann, 2003). The adverse effect of pesticides may also include soil fertility (Schuster and Schroder, 1990). An ideal pesticide should be biodegradable and toxic to only the target organism (Chowdhury et al., 2008). When pesticides are applied in the environment, they undergo transformation 
processes, these transformations are carried out by various mechanisms like physical, chemical and biological agents where microorganisms play a key role. The transformation mechanism includes oxidation hydrolysis reduction conjugation etc, catalyzed by various types of enzymes. The chemical and physical properties of pesticide are an important factor in degradation process (Beigel et al., 1999). The degradation process is associated with abiotic as well as biotic components; the latter has received much attention (Hafez and Theimann, 2003). Therefore, microbial community in soil is important in degrading the pesticides as well as maintaining soil health by carrying out various functions.

\section{Factors affecting degradation/ transformation of pesticides}

\section{Pesticide structure}

The inherent biodegradability of a pesticide is determined by its structure due to its physical and chemical properties. Introduction of polar groups on phenyl ring viz. $\mathrm{OH}, \mathrm{COOH}$ and $\mathrm{NH}_{2}$ makes the compound subject to microbial attack which enhances degradation process (Chowdhury et al., 2008). The presence of halogen or alkyl substituent have a tendency to make the molecule more resistant more resistant to biodegradation (Cork and Krueger, 1991). Chlorinated hydrocarbons such as DDT are insoluble in water so are relatively lesser biodegradable (Fig. 1).

\section{Pesticide concentration}

Pesticide concentration plays an important role in determining the rate of biodegradation process. The rate of degradation process decreases proportionally with the increased pesticide concentration as most of the pesticides follow first order reactions (Topp et al., 1997).

\section{Soil moisture}

Water dissolves the pesticides and help in its movement, diffusion and microbial activities. Therefore pesticide degradation is slow in dry soils. The rate of pesticide transformation is also increased with water content.

\section{Temperature}

Adsorption and hydrolysis of pesticides in soil is highly affected by temperature as it affects the solubility of the substance (Racke et al., 1997).

Microbial activity is encouraged by increase in temperature. The maximum growth and activity of microorganisms in soil occur at 25 $-35^{\circ} \mathrm{C}$ (Alexander, 1997) and degradation of pesticide is optimum at $25-40^{\circ} \mathrm{C}$ (Topp et al., 1997).

\section{Soil pH}

Pesticide adsorption, abiotic and biotic degradation processes are affected by soil $\mathrm{pH}$ (Burns, 1975). Transformation, mobility and bioavailability of pesticides are influenced by change in pH. Topp et al., 1997 reported higher sorption of prometryn to clay montmorillonite at $\mathrm{pH} 3$ than at $\mathrm{pH} 7$.

\section{Impact on soil microbial diversity}

The effects of pesticides on the soil microflora are of importance because various microbial functions are critical to crop production, soil sustainability, and environmental quality (Imfeld and Vuilleumier, 2012). Biological decomposition of pesticides is the most important and effective way to remove these compounds from the environment. Microorganisms have the ability to interact, both chemically and physically, with substances leading to structural changes or complete degradation of the target molecule. 
Among the microbial communities, bacteria, fungi, and actinomycetes are the main transformers and pesticide degraders (Diez, 2010). Microbial biomass is an important indicator of microbial activities and provides direct assessment of the linkage between microbial activities and the nutrient transformations and other ecological processes (Schultz and Urban, 2008). Pesticides in soil undergo a variety of degradative, transport, and adsorption/desorption processes depending on the chemical nature of the pesticide and soil properties (Laabs et al., 2007). Pesticide reduces microbial diversity but increases functional diversity of microbial communities (Wang et al., 2006). Pesticides also inhibit or kill certain group of microorganisms and outnumber other groups by releasing them from the competition (Chen and Edwards, 2001).

On positive aspects, pesticides may act as a source of energy and nutrients to multiply for some groups of microorganisms (Johnsen et al., 2001). When applied in recommended doses, some pesticides have been reported to be increasing the microbial population, beyond that, there is adverse effect on microbial population (Nasreen et al., 2015). They have reported increasing microbial population with the increase in insecticides namely endosulfan and profenofos of bacteria, fungi and actinomycetes up to recommended doses. Newman et al., 2016 have also reported increase in abundance of Proteobacteria but decrease in relative abundance of acidobacteria in corn rhizosphere samples.

A decrease in the diversity of soil algal population was observed and native cyanobacteria are replaced by more resistant green algae in soils contaminated by the insecticide DDT (Mallavarapu, 2002). Protozoa have great impact on population of microbes as they are the microbial predator maintaining the population pressure in the ecosystem. They are quite sensitive to pesticide application. Negative impact of pesticide application on the colonization of soil protozoa have been reported (Ekelund $e t$ al., 1994). Similar results of decreasing protozoa population after application of Thiodan and Karate at high concentrations have been reported by Adebavo et al., (2007).

\section{Effect of pesticides on soil enzymatic activities}

The effect of pesticides on soil enzymes particularly extracellular enzymes are dense due to their different behavior in complex soil medium. Negative impact of pesticides on soil enzymes like hydrolases, oxidoreductases, and dehydrogenase activities has been widely reported (Monkiedje and Spiteller, 2002). Soil enzymatic activities and ATP contents are increased by some pesticides (Megharaj et al., 1999). Yang et al., 2007 observed variable effect of pesticides and mercury on urease enzyme, with the concentration of furadon, urease activity increased meadow burozem soils whereas urease activity increased at the low concentration, then decreased with an increase in the concentration of furadan in phaeozem soil. The joint effect of $\mathrm{Hg}+$ chlorimuron-ethyl and $\mathrm{Hg}+$ furadon could significantly reduce the activity of soil urease, and the inhibition effect was enhanced with increasing concentrations

\section{Impact of bio-pesticides on soil microbial diversity and enzymes}

Antagonist alters the microbial community structure when they are applied to small habitats and this might affect plant growth and soil microbial process (Pfender et al., 1996). Being an active compost activator, use of Trichoderma has helped in improving the water holding capacity thus improving physical condition of soils by promoting soil aggregation. 
Fig.1 Factors affecting degradation/transformation of pesticides

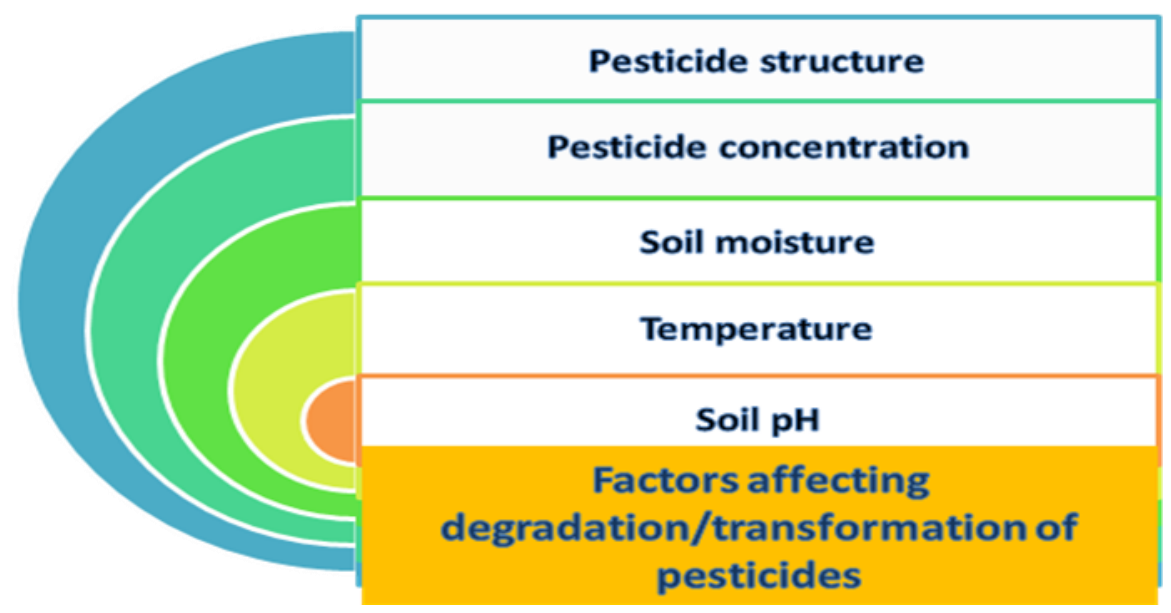

Trichoderma is imperative to conserving soil microbial fauna and flora (Singh and Sharma 2012).

A negative effect of Paenimyxin on the bacterial colony forming unit (CFU) was observed after 2 and 4 days of application while the effect on bacteria after 7 days of treatment was negligible. Moreover, Paenimyxin did not affect the denitrifying bacterial community (Sameh et al., 2007). In another study, Azadirachtin granules (alcoholic extract of neem seed kernel mixed with China clay) at recommended dose suppressed the bacterial population in the initial 15 days, and later had an enhancing effect by the $90^{\text {th }}$ day, whereas higher doses had a negative impact compared to the normal dose, which was however, on par with control. The actinomycetes and azotobacter population also responded similarly. Azadirachtin granules did not have significant effect on dehydrogenase activity though the same dose had significantly increased bacterial, actinomycetes and azotobacter population (Gopal et al., 2007).

Different chemicals have different effects on different microorganisms and enzymatic activity. Further studies on variety of chemicals are vital as they have different effect on different soil. Comparison study of chemical and biopesticide on the same soil can give clear perspective to the recommendation for future application. Understanding the mechanisms underlying molecular responses in microbes in response to pesticides application could be helpful in studying the impact of pesticides in soil. Studying the impact of biopesticides on plants directly is indispensable to conclude if biopesticides are safe to use in the future

It is difficult to grasp the role of pesticides in disturbing soil environment due to divergent research findings reported earlier. Some pesticides residues could be used by specific microorganisms as carbon or energy source and are degraded and assimilated by them, but several reports reveal their deleterious effects on soil microorganisms as well. Generally, long-term application of pesticides can disturb biochemical equilibrium which can reduce soil fertility and productivity. On the other hand, application of biopesticides has improved the soil health indirectly by maintaining natural balance with some exceptions, so thorough study of the impact of biopesticides on soil ecosystem must be accomplished before application. Consequently, application of biopesticides along with natural soil amendments (compost, manure, vermicompost etc.) can be used as an alternative to chemical pesticides without deteriorating the environment but complete removal of chemical pesticides may not be advisable as biopesticides are slow in action. 


\section{References}

Adebavo, T.A., Oio, O.A. and Olaniran, O.A. 2007. Effect of two insecticides Karate and Thiodan on population dynamics of four different soil microorganisms. Research Journal of Biological Sciences 2(5): 557- 560.

Alexander, M. 1977. Introduction to soil microbiology. $2^{\text {nd }}$ Edn. Wiley Eastern Limited, New Delhi.

Antonious, G. F. 2003. Impact of soil management and two botanical insecticides on urease and invertase activity. Journal of Environmental Science and Health Part B 38: 479-488.

Beigel, C., Charnay, M.P. and Barriuso, E. 1999. Degradation of formulated and unformulated triticonazole fungicide in soil: effect of application rate. Soil Biology and Biochemistry 31: 525-534.

Burns, R.G. 1975. Factors affecting pesticides loss from soil. In: Soil Biochemistry. Vol. 4 Paul, E. A. and McLaren, A. D (eds.). Marcel Dekker, Inc., New York. USA. Pp. 103-141.

Chen, S.K., and Edwards, C.A. 2001. A microcosm approach to assess the effects of fungicides on soil ecological processes and plant growth: Comparison of two soil types. Soil Biology and Biochemistry 33: 1981-1991.

Chowdhury, A., Pradhan, S., Saha, M. and Sanyal, N. 2008. Impact of pesticides on soil microbiological parameters and possible bioremediation strategies. Indian Journal of Microbiology 48: 114-127.

Cork, D.J. and Krueger, J.P. 1991. Microbial transformations of herbicides and pesticides. Advances in Applied Microbiology 36: 1-66.

Diez, M.C. 2010. Biological aspects involved in the degradation of organic pollutants. Journal of Soil Science and Plant Nutrition. 10(3): 244 - 267.

Ejaz, S., Akram, W., Lim, C.W., Lee, J.J. and Hussain, I. 2004. Endocrine disrupting pesticides: a leading cause of cancer among rural people. Experiment Oncology 26: 98-105.

Ekelund, F., Ronn, R. and Christensen, S. 1994. The effect of three different pesticides on soil protozoan activity. Pesticide Science 42(2): 71-78.

Gopal, M., Gupta, A., Arunachalam, V., Magu, S.P. 2007. Impact of azadirachtin, an insecticidal allelochemical from neem on soil microflora, enzyme and respiratory activities. Bioresource Technology 98: 3154-3158.

Gupta, S., Gupta, R. and Sharma, S. 2013. Impact of chemical- and bio-pesticides on bacterial diversity in rhizosphere of Vigna radiate. Ecotoxicology 22: 1479-1489.

Hafez, H.F.H. and Theimann, W.H.P. 2003. Persistence and biodegradation of iazinone and imidacloprid in soil. Proc. XII Symp. Pest. Chem., Congress Centre Universita Cattolica, Via Emilia Parmense 84, Piacenza. Pp. 35-42.

Imfeld, G., and Vuilleumier, S., 2012. Measuring the effects of pesticides on bacterial communities in soil: a critical review. European Journal of Soil Biology 49: 22-30.

Johnsen, K., Jacobsen, C.S., and Torsvik, V. 2001. Pesticides effects on bacterial diversity in agricultural soils-A review. Biology and Fertility of Soils 33: 443453.

Laabs, V., Wehrhan, A., Pinto, A., Dores, E., and Amelung, W. 2007. Pesticide fate in tropical wetlands of Brazil: An aquatic microcosm study under semi-field conditions. Chemosphere 67: 975-989.

Mahía, J., Cabaneiro, A., Carballas, T. and Díaz-Raviňa, M. 2008. Microbial biomass and $\mathrm{C}$ mineralization in agricultural soils as affected by atrazine addition. Biology and Fertility of Soils 45: 99-105.

Mallavarapu, M. 2002. Heavy pesticide use lowers soil health. Farming Head 121: 37-38.

Megharaj, M., Boul, H. L., and Thiele, J. H. 1999. Effects of DDT and its metabolites on soil algae and enzymatic activity. 
Biology and Fertility of Soils 29: 130134.

Monkiedje, A. and Spiteller, M. 2002. Effects of the phenylamide fungicides, mefenoxam and metalaxyl, on the biological properties of sandy loam and sandy clay soils. Biology and Fertility of Soils 35: 393-398.

Nasreen, G., Mohiddin, J., Srinivasulu M., Manjunatha, B., and Rangaswamy, V. 2015. Interaction Effects of Insecticides on Microbial Populations and Dehydrogenase Activity in Groundnut (Arachis hypogeae L.) Planted Black Clay Soil C. International Journal of Current Microbiology and Applied Sciences 4(2): 135-146.

Newman, M.M., Hoilett, N., Lorenz, N., Dick, R.P., Liles, M.R. Ramsier, C. and Kloepper, J.W. 2016. Glyphosate effects on soil rhizosphere-associated bacterial communities. Science of the Total Environment 543: 155-160.

Pfender, W., Fieland, V., Ganio, L. and Seidler, R. 1996. Microbial Community Structure and Activity in wheat straw after inoculation with Biological Control Organisms. Applied Soil Ecology 3: 6978.

Racke, K.D., Skidmore, M.W., Hamilton, D.J., Unsworth, J.B., Miyamoto, J. and Cohen, S.Z. 1997. Pesticide fate in tropical soils. Pure and Applied Chemistry 69: 1349 1371.

Sameh, S., Fabrice, M. L., Nadine, R., Silvio, G., and Diederik, V. T. 2007. Impact of a new biopesticide produced by Paenibacillus sp. strain B2 on the genetic structure and density of soil bacterial communities. Pest Management Science 63: 269-275.
Schultz, P., and Urban, N.R. 2008. Effects of bacterial dynamics on organic matter decomposition and nutrient release from sediments: A modeling study. Ecological Modelling 210: 1-14.

Schuster, E. and Schroder, D. 1990. Side-effects of sequentially applied pesticides on nontarget soil microorganisms: field experiments. Soil Biology and Biochemistry 22: 367-373.

Singh, M., and Sharma, O.P. 2012. Trichoderma- a savior microbe in the era of climate change. International Journal of Advanced Biological Research 2(4): 784-876.

Topp, E., Vallayes, T. and Soulas, G. 1997. Pesticides: Microbial degradation and effects on microorganisms. In: Modern soil microbiology. Van Elsas JD, Trevors JT and Wellington EMH (eds.). Mercel Dekker, Inc. New York. USA. Pp. 547575.

Wang, M.C., Gong, M., Zang, H.B., Hua, X.M., Yao, J., Pang, Y.J., and Yang, Y.H. 2006. Effect of methamidophos and urea application on microbial communities in soils as determined by microbial biomass and community level physiological profiles. Journal of Environmental Science and Health Part B 41: 399-413.

Wilson, C. 2000. Environmental and human costs of commercial agricultural production in South Asia. International Journal of Social Economics 27: 816846.

Yang, C., Sun, T., He, W., Zhou, Q., and Chen, S. 2007. Single and joint effects of pesticides and mercury on soil urease. Journal of Environmental Sciences. 19: 210-216.

\section{How to cite this article:}

Yumnam Bijilaxmi Devi, Thounaojam Thomas Meetei and Nirmala Kumari. 2018. Impact of Pesticides on Soil Microbial Diversity and Enzymes: A Review. Int.J.Curr.Microbiol.App.Sci. 7(06): 952-958. doi: https://doi.org/10.20546/ijcmas.2018.706.113 